\section{TRES EDIFICIOS DE COMUNICACIONES ESPAÑA}

\author{
Juan Salabert Sancho, Arquitecto \\ 145-109
}

\section{SINOPSIS}

En este artículo se presentan tres edificios de comunicaciones para la Dirección de Correos y Telecomunicación, situados en Albacete, Jerez de la Frontera y Santa Cruz de Tenerife.

Estos proyectos se caracterizan por su ajustada funcionalidad que viene dada por la distribución de los espacios, por las correctas circulaciones y por su adecuación al entorno urbanístico.

Se describen detalladamente las principales características de estas obras, la distribución de los distintos servicios y algunos de sus detalles constructivos más interesantes.

\section{Edificio de comunicaciones Albacete}

El edificio de Comunicaciones de Albacete se construyó en un terreno dotado de todos los servicios urbanisticos y de una superficie aproximada de $2.000 \mathrm{~m}^{2}$.

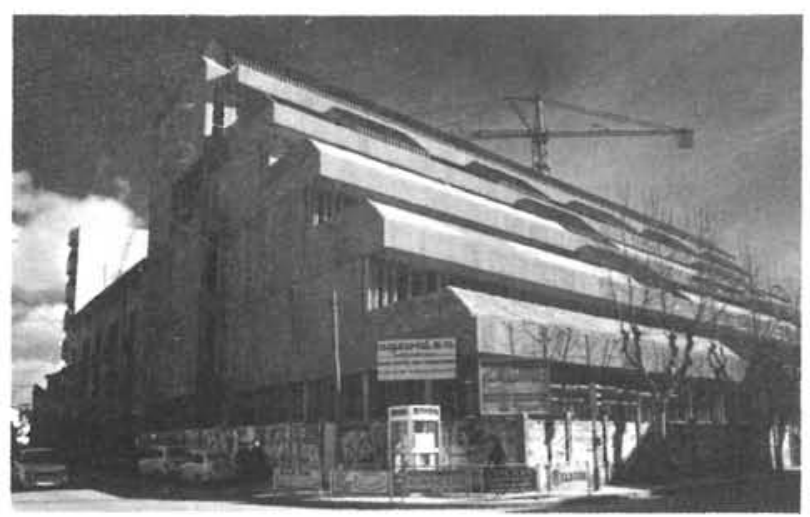

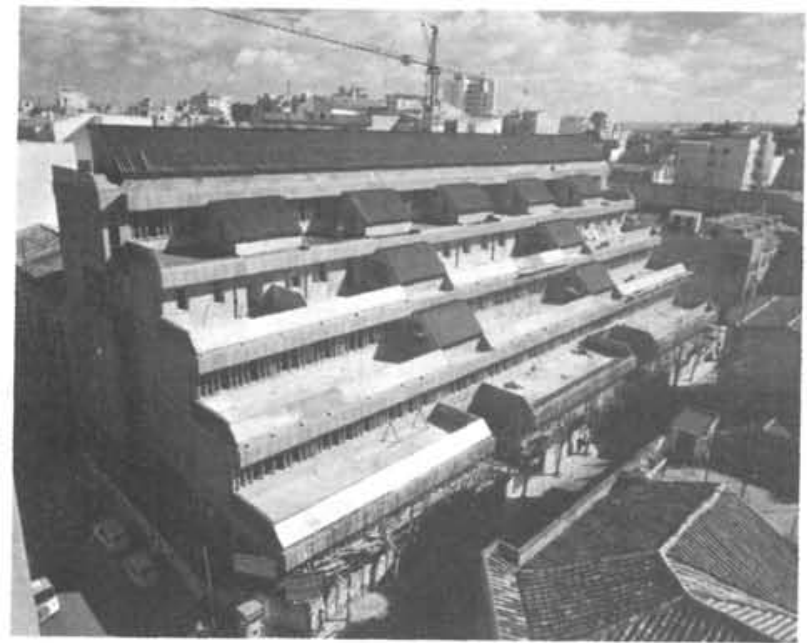

El terreno completamente llano y de forma rectangular perfecta tiene tres fachadas a las calles Marqués de Villores, Abelardo Sánchez y Dionisio Guardiola, mientras que la cuarta es una medianería.

Para la realización de esta obra hubo que tener en cuenta una serie de condicionantes como calles y aceras estrechas, alta densidad, su radicación en el centro urbano, necesidad de adosarse a las medianerias existentes en la parte norte, así como obligada organización lineal derivada de la forma de la parcela.

Con objeto de evitar que el edificio diera sensación de una "pared" lineal, debido a la gran longitud de la fachada que da a la calle Guardiola, asi como a la poca longitud de éste, se buscó la solución de retranqueos sucesivos en las diferentes plantas a medida que se superponen. La tangente a estos retranqueos tiene una inclinación de $45^{\circ}$ respecto a la vertical.

En cuanto a la solución de adosarse por la parte norte a los edificios existentes, a pesar de la gran superficie del solar, se debió al mal efecto que produciria la visión libre de dichas medianerias.

Para aumentar la capacidad de carga y descarga de los muelles y eliminar parte de la 

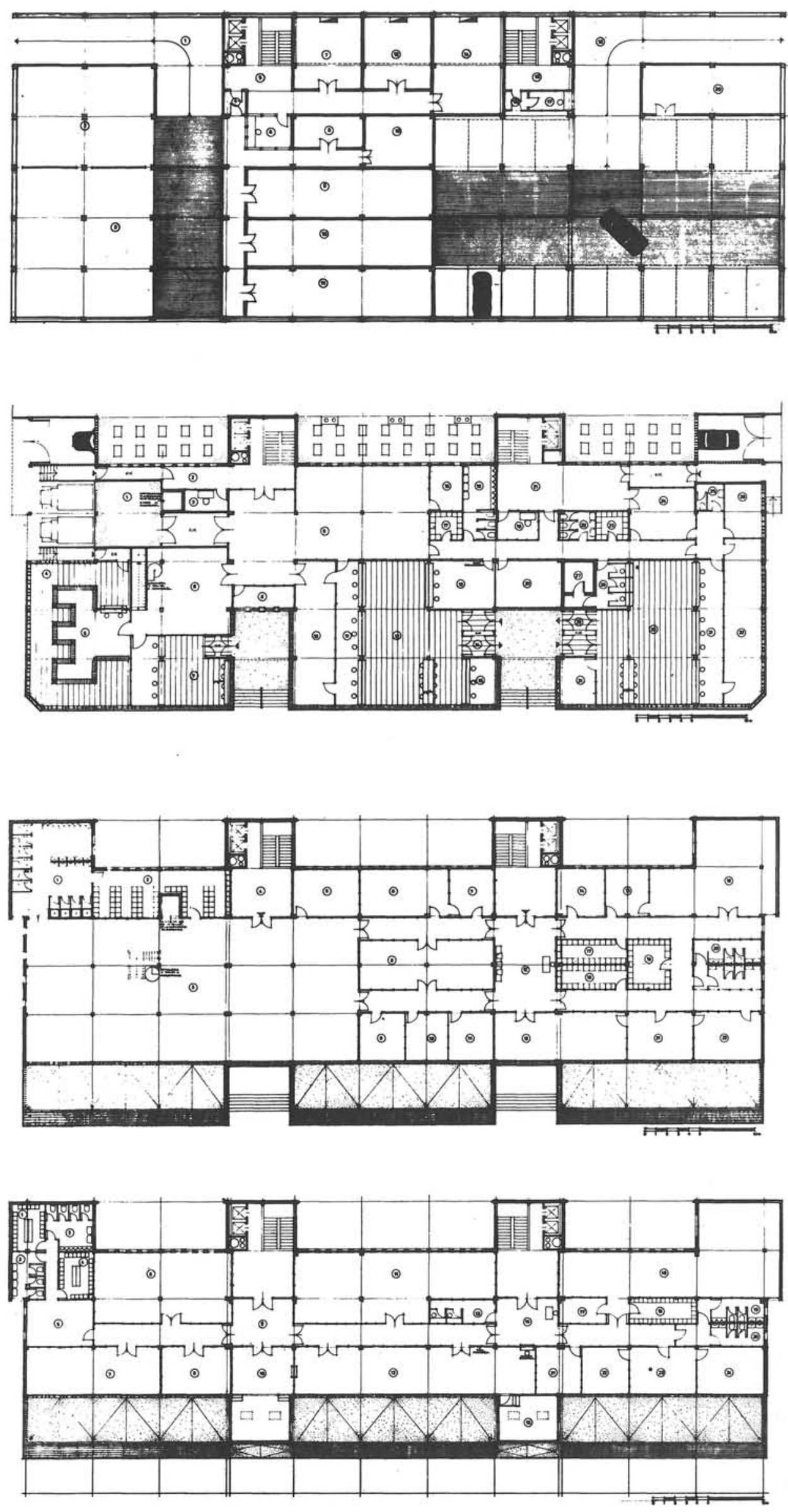

\section{planta de semisótano}

1.-Rampa. 2.-Motos. 3.-Furgones de servicio. 4.-Cortafuegos. 5.-Vestibulo. 6.-Control. 7.-Grupo electrógeno. 8.- Almacén-conservación. 9.-Almacén-correos. 10.-Almacén-telecomunicación. 11.-Almacéntineas telecomunicación. 12.Celda de transformación. 13.Archivo-giro postal. 14.-Baterias. 15. - Vestibulo. 16.-Cortafuegos. 17.-Control. 18.-Rampa. 19.-Aparcamiento. 20.-Almacén.

\section{planta baja}

1.-Muelle. 2.-Vestibulo. 3.Control. 4.-Vestibulo-apartados. 5.-Apartados (1.600). 6.Negociado de paqueteria. 7.Vestibulo-paquetes. 8.-Buzones. 9.-Sala de Dirección. 10.Negociado de certificados y giro postal. 11.-Correos. 12.-Vestibulo-correos y telégrafos. 13.-Telégrafos. 14.-Cortavientos. 15. - Información y venta de sellos. 16. - Despacho Jefe S. de D. 17.-Roperos. 18.Aseos caballeros. 19. - Control. 20.-Retén policia. 21.-Vestibulo. 22,-Aseos señoras. 23.-Roperos. 24.-Secretaria C.P.A. 25.-Aseos. 26.-Despacho Jefe C.P.A. 27. - Cámara acorazada. 28.-Caja. 29.-Cortavientos. 30.-Vestibulo C.P.A. 31. - Caja Postal de Ahorros. 32.-Oficina C.P.A.

\section{planta primera}

1.-Aseos. 2.-Vestuario. 3.Carteria. 4.-Vestibulo. 5.-Descanso. 6.-Habilitación. 7.- Habilitado. 8.-Almacén-material impresos. 9.- Jefe carteria. 10.- Jefe servicios tráfico. 11.Disponible. 12.-Vestibulo. 13.Sala de Juntas. 14.-Subinspector. 15. - Interventor 20 Jefe. 16. - Intervención (servicios bancarios). 17. - Archivo bancario. 18.- Archivo secretaria. 19.-Armarios roperos, 20.-Aseos. 21.-Secretaria. 22.-Administrador.

\section{planta \\ segunda}

1.-Vestuario caballeros. 2.Aseo caballeros. 3.-Aseo señoras. 4.-Vestuario señoras. 5.-Descanso. 6.-Personal de vigilancia. 7.- Habilitación. 8.Taller. 9.-Vestibulo. 10.-Reparto. 11. - Sala de centrales y equipo 12. - Sala de aparatos. 13.-Cabinas Télex. 14.-Vesti13.- Cabinas Télex. 14.-Vesti-
bulo. 15. - Telebèn y curso mixto. 16.-Oficinas generales. 17.-Archivo. 18.-Ropero. 19.Aseo caballeros. 20.-Aseo señoras. 21.-Ayudantes S. T. 22. - Jefe de tráfico. 23.-Antedespacho y secretaria. 24,-Delegado Jefe de Centro. 


\section{planta tercera}

A. Vivienda conserje $1.01,-$ Tendedero. 2,-Vestibulo. 3.Distribuidor. 4.-Estar-comedor. 5.-Cocina. 6.-Baño. 7, 8 y 9.-Dormitorio. 10 y 11.-Terraza. B. Vivienda conserje $2 .^{\circ}$ 12.-Tendedero, 13,-Vestibulo. 14.-Distribuidor, 15. - Estarcomedor 16. Cocina. 17. Ba ño. 18,19 y 20. -Dormitorio. 21.-Terraza. C. Vivienda Jefe 1. 22.-Vestibulo. 23.-Distribuidor. 24.-Estar-comedor-despacho. 25, 26, 27 y 28.-Dormitorio. 29.-Juegos niños. 30 31. 31. - Bano. 32. - Aseo. 33.Cuarto de servicio-plancha. 34.-Tendedero. 35.-Cocina. 36.-Despensa. 37.-Terraza. D. Vivienda Jefe $2 .^{\circ}$. 38.-Vestibulo. 39.-Distribuidor. 40,-Estar-comedor-despacho 41, 42 , 43 y 44 -Dormitorio 45 - Juegos niños. 46 y $47,-B$ año gos niños. 46 y 47.- Baño. vicio-plancha. 50.-Tendedero. 51.-Cocina. 52.-Despensa. 53 y 54.- Terraza.

\section{planta cuarta}

1 y 2.-Aula. 3.-Almacén. 4.Club. 5.-Vestibulo-distribuidor 6.-Aseos señoras. 7.-Aseos caballeros. 8.-Bar. 9.-Vestibulo-distribuider, 10,-Aseos señoras. 11, Aseos caballeros. Depósito de libros. 14.-Salón de Actos.
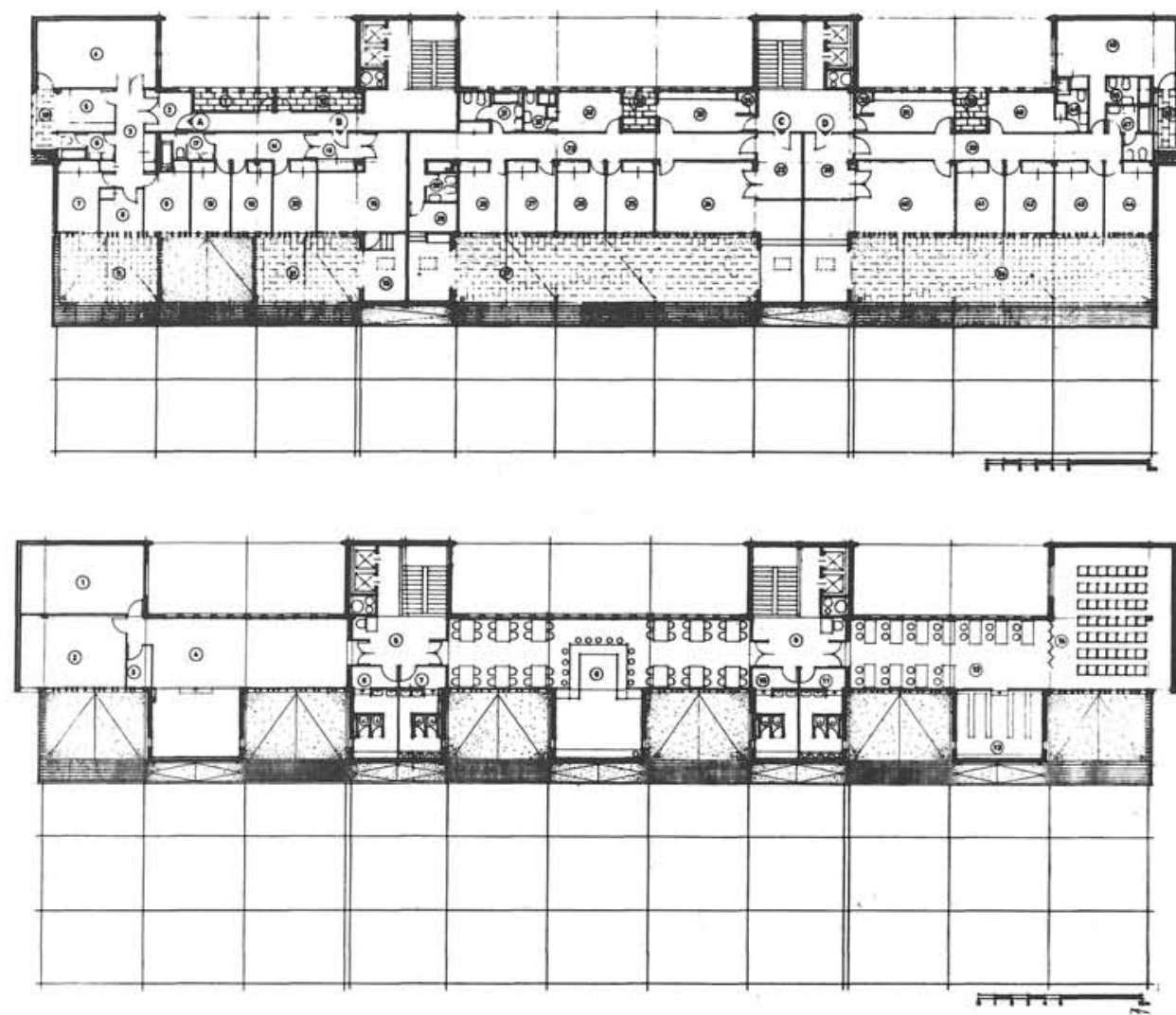

congestión peatonal se ampliaron los accesos de las calles laterales retranqueando las fachadas del edificio en su mayor parte.

Este edificio está formado por planta semisótano, planta baja y cinco plantas superiores cuyo esquema de funcionamiento es el siguiente:

\section{Planta semisótano}

La mayor parte de esta planta ha sido destinada a dos aparcamientos: uno para turismos y otro para velomotores y furgones de los servicios. Entre ambos aparcamientos se encuentran una sala de energía, almacén de útiles de conservación, archivo de giro postal, almacén de correos y almacén de telecomunicación y lineas.

\section{Planta baja}

La fachada principal se fracciona en tres cuerpos, cada uno de ellos con su propio vestíbulo público y el central destinado a Telégrafos y servicio principal de Correos, y los otros dos: uno para la Caja Postal de Ahorros y el otro para paqueteria de apartados postales. Estos tres vestíbulos tienen comunicación interior con la Sala de Dirercción.

El resto de los espacios de esta planta se destinan a oficinas de la Caja Postal y negociados.

La distribución de accesos es la siguiente: Entre los tres vestíbulos se originan dos patios exteriores que dan a la fachada principal. En el de la izquierda se sitúan los buzones y el acceso al vestíbulo de paquetería, y en el de la derecha las entradas a los vestíbulos de Correos-Telégrafos y la Caja Postal de Ahorros.

En la fachada lateral derecha hay un acceso a la escalera y ascensores principales que sirven a las zonas "nobles", y las viviendas del personal directivo, así como a los funcionarios de la Caja y al servicio telegráfico nocturno.

En la fachada lateral izquierda se alinean el acceso al vestíbulo de apartados y lista, el muelle para dos furgones y una entrada para funcionarios y conserjes.

\section{Planta Primera}

Destinada totalmente a Correos está dividida en dos zonas: la de la izquierda ocupada por Cartería y la de la derecha por oficinas de funcionarios. Como espacios auxiliares figuran aseos, vestuarios, archivos y almacén de material-impresos. 

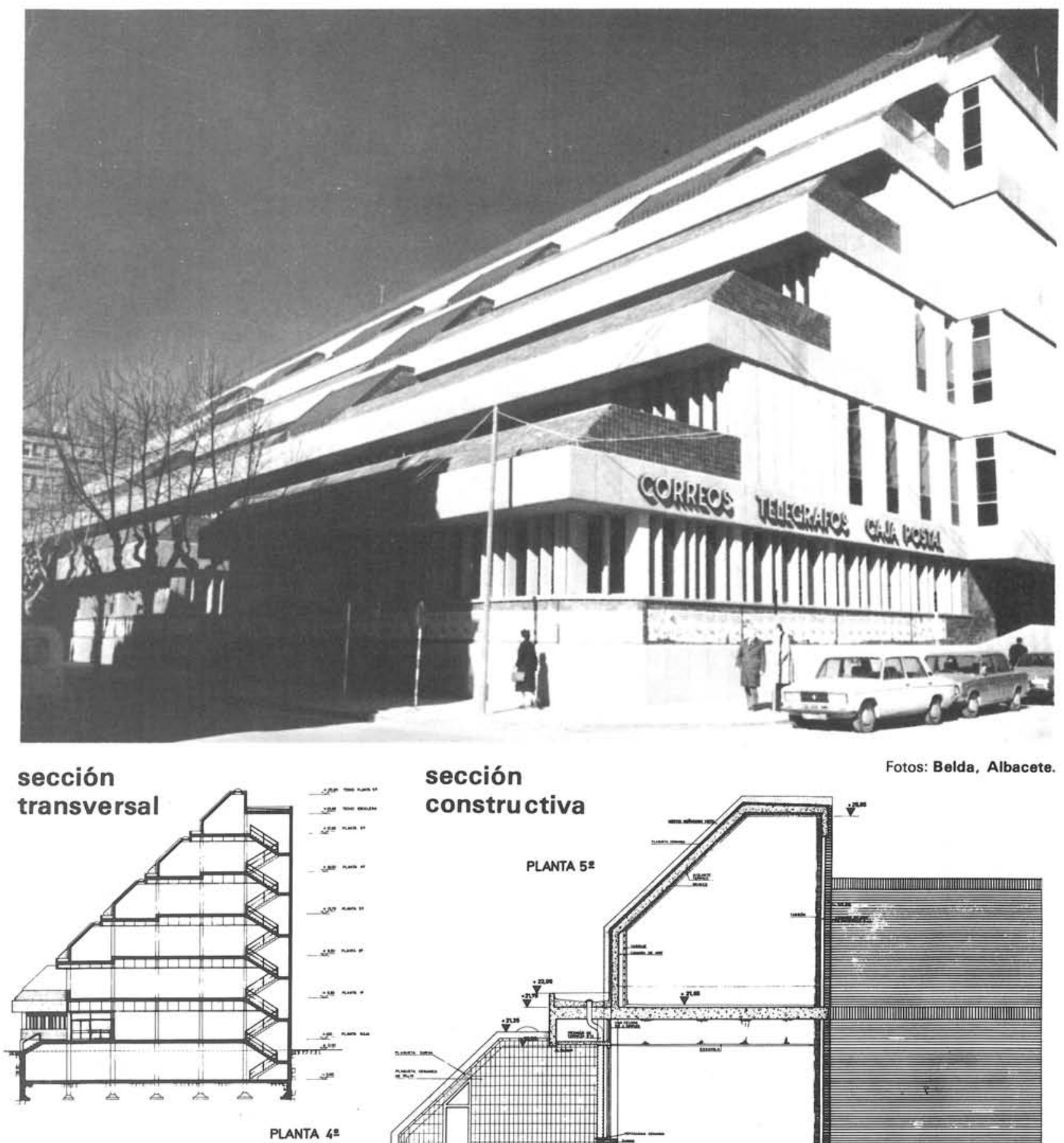

constructiva

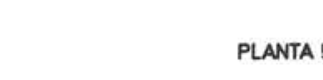




\section{Planta Segunda}

Se ha destinado a Telégrafos. Contiene una sala de Apartados, un Teleben y Curso Mixto, asi como cabinas públicas de Télex.

\section{Planta Tercera}

Consta de cuatro viviendas; dos para el personal directivo y dos para conserjes.

\section{Planta Cuarta}

Ocupada en su parte central por un bar con sus servicios correspondientes. En la zona servida por la escalera principal se disponen la biblioteca y un pequeño salón de actos, mientras en el lado opuesto hay un Club y unas aulas, que pueden ser utilizadas como guarderia infantil.

\section{Planta Quinta}

Reservada para la maquinaria de aire acondicionado, cuarto de maquinaria para los aparatos elevadores y espacios disponibles para almacenaje, trasteros o archivos.

Los sistemas, materiales y elementos constructivos utilizados en este edificio fueron los siguientes: cimentación y muros de contención de hormigón armado, soportes de acero laminado, forjados reticulares bidireccionales, fachada combinando estructuras en hormigón visto in situ con paneles de cerramiento de hormigón prefabricado, fachada al patio de manzana en ladrillo cara vista, planos inclinados y petos de terrazas revestidos de plaqueta de gres, cubiertas con acabado de grava y pavimento general de terrazo $40 \times 40$ en china fina y tonos oscuros, falsos techos de plancha lisa de escayola con foseado perimetral y alojamiento empotrado de luminarias y espacios exteriores solados con baldosa de árido lavado alternando con pavimentos de goma en porches de acceso. La carpinteria exterior es de aluminio con junquillos, también de aluminio, sobre precerco de madera, y las divisiones interiores se realizaron a base de mamparas hechas con tabicón y tubo de hierro pintado al esmalte.

La distribución vertical del acondicionamıento de aire se realizó a través de los núcleos de circulaciones verticales, mientras que para la horizontal se utilizó el hueco existente entre el cielo raso de escayola y el forjado.

\section{Pabellón postal en la estación férrea de Jerez de la Frontera/Cádiz}

El pabellón postal de la estación de ferrocarril, en Jerez de la Frontera, consta de un centro de clasificación, servicio de paqueteria, estafeta de correos y cartería urbana,
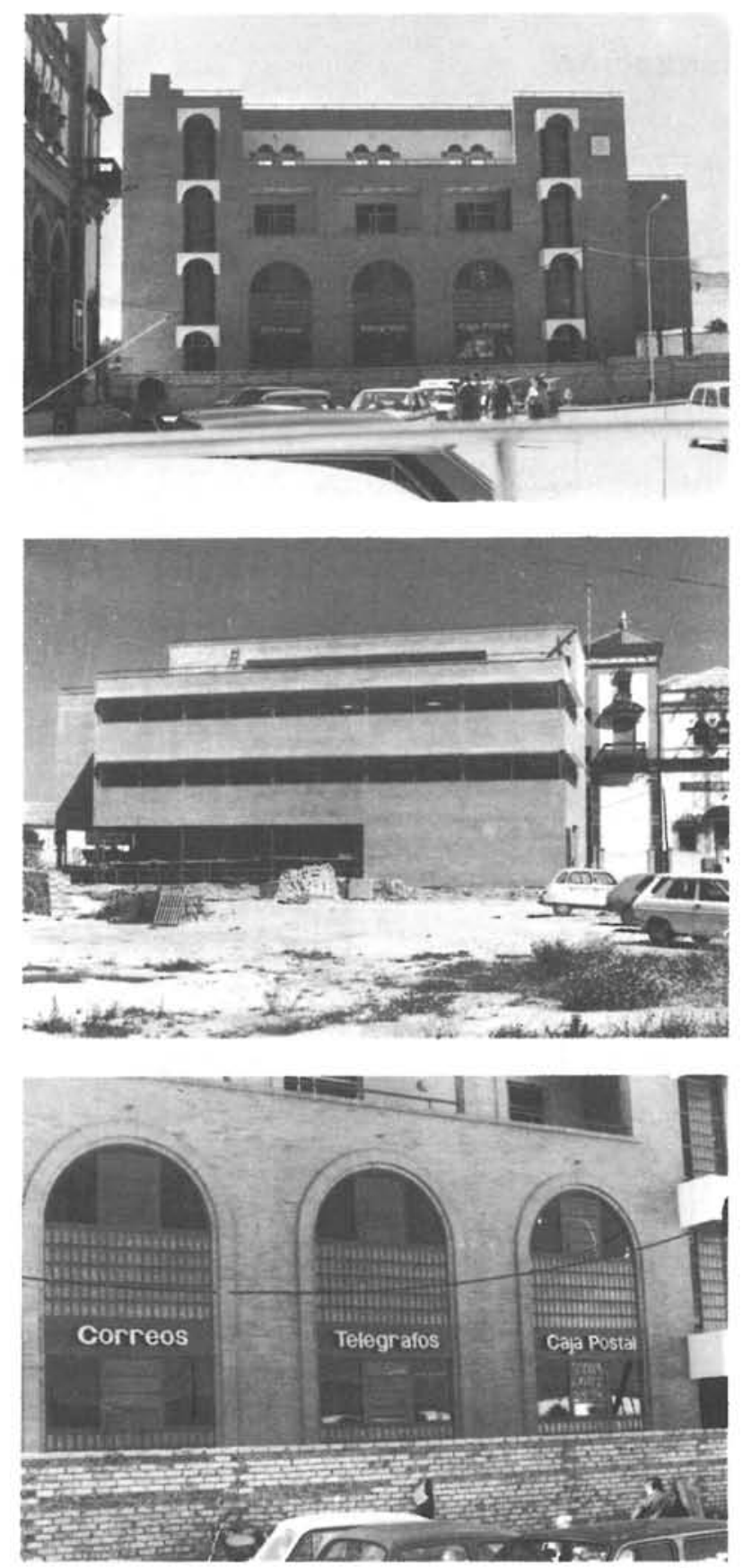


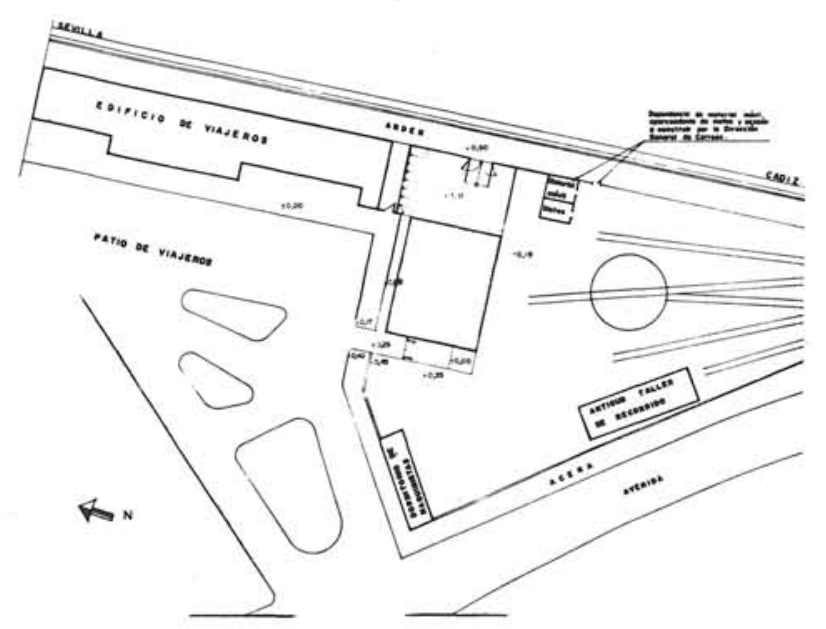

situación

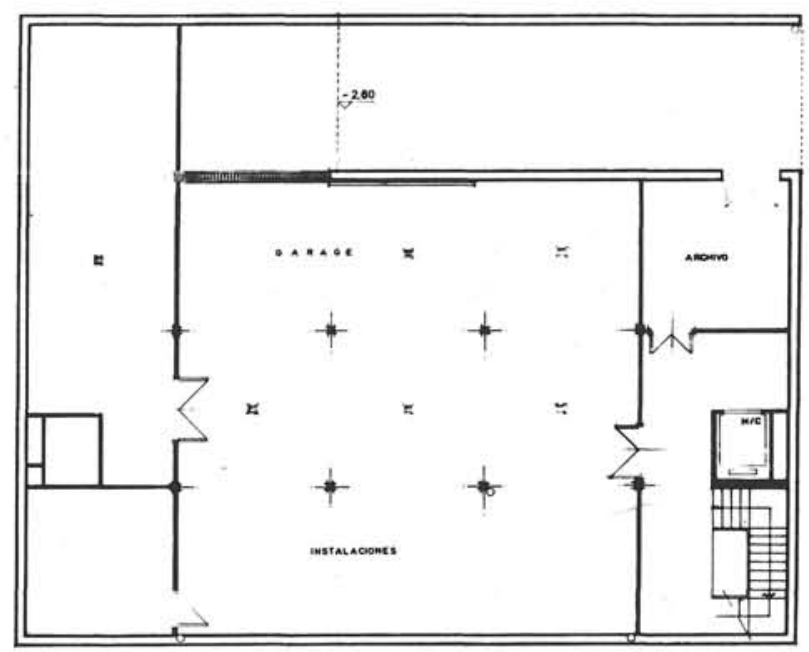

planta sótano $(-2,80 \mathrm{~m})$

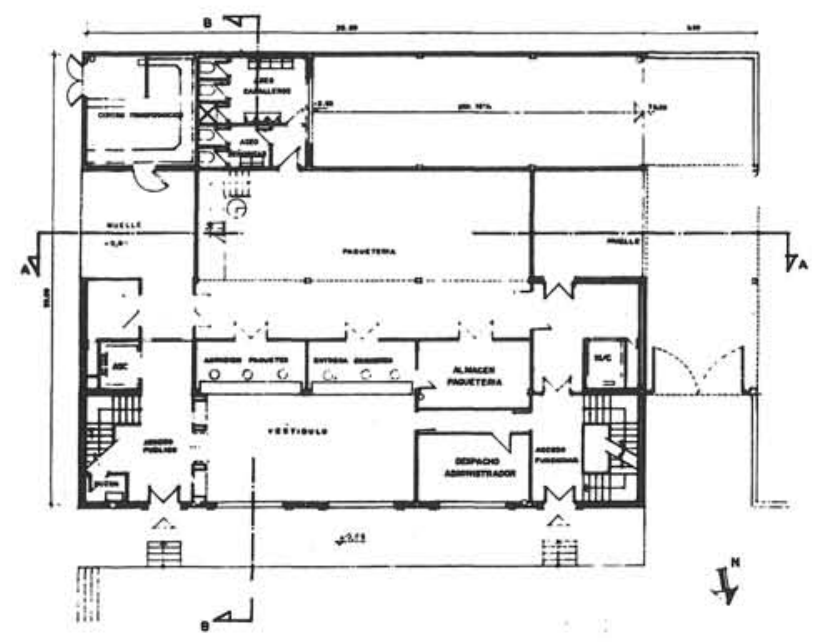

planta baja $(+0,70 \mathrm{~m})$

además de vivienda para funcionarios en labor de vigilancia o dirección y un aparcamiento

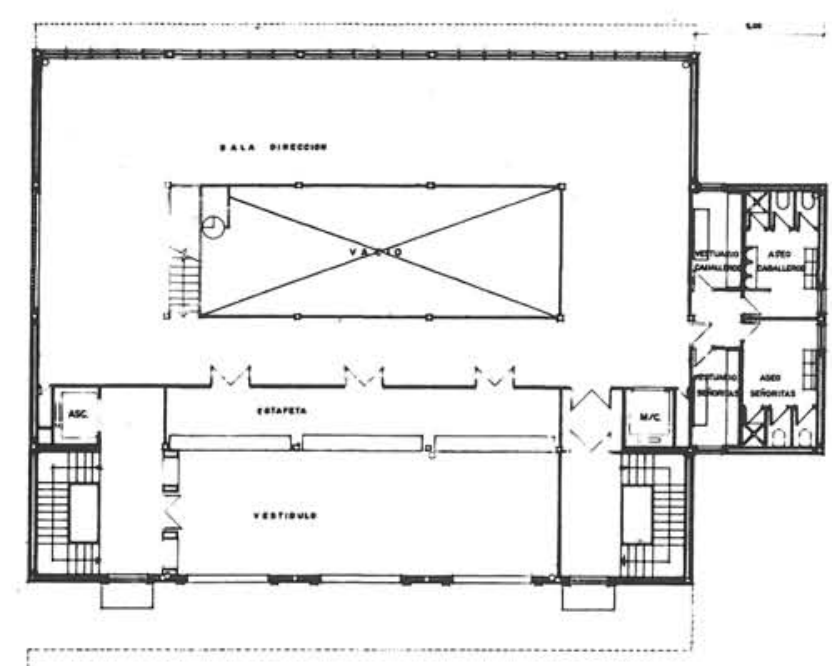

planta primera $(+4,20 \mathrm{~m})$

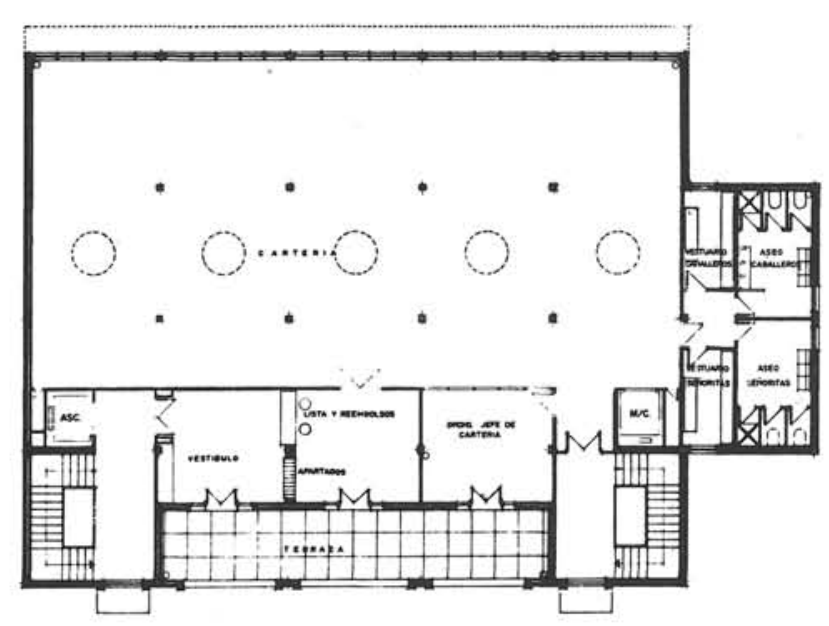

planta segunda $(+7,70 \mathrm{~m})$

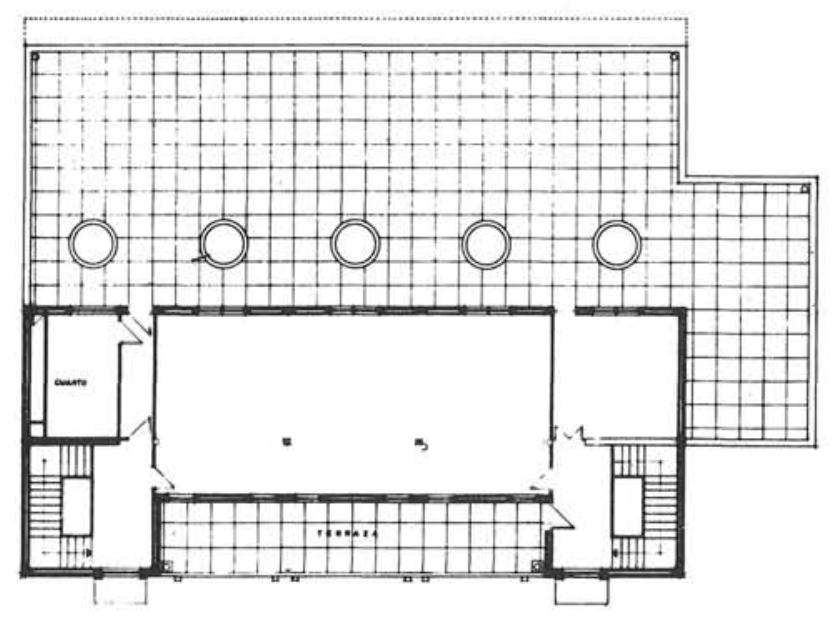

planta tercera $(+11,20 \mathrm{~m})$

para vehículos de los servicios postales en la planta sótano. 
Para la construcción del pabellón, Renfe cedió una parcela rectangular, de topografia plana y dimensiones $30 \times 20 \mathrm{~m}$, contigua al servicio de viajeros cuya fachada norte linda con la plaza de la estación.

En la composición exterior del edificio se tuvo muy en cuenta la armonía con el edificio principal de viajeros integrando en la fachada norte, que da a la plaza, elementos similares a los de éste. Los materiales de fachada intentan armonizar con los del edificio principal.

Este edificio está formado por sótano, planta baja y tres plantas superiores cuyo esquema de funcionamiento es el siguiente:

\section{Planta sótano}

Comprende un garaje, archivo y espacio para las instalaciones del edificio. Los accesos a

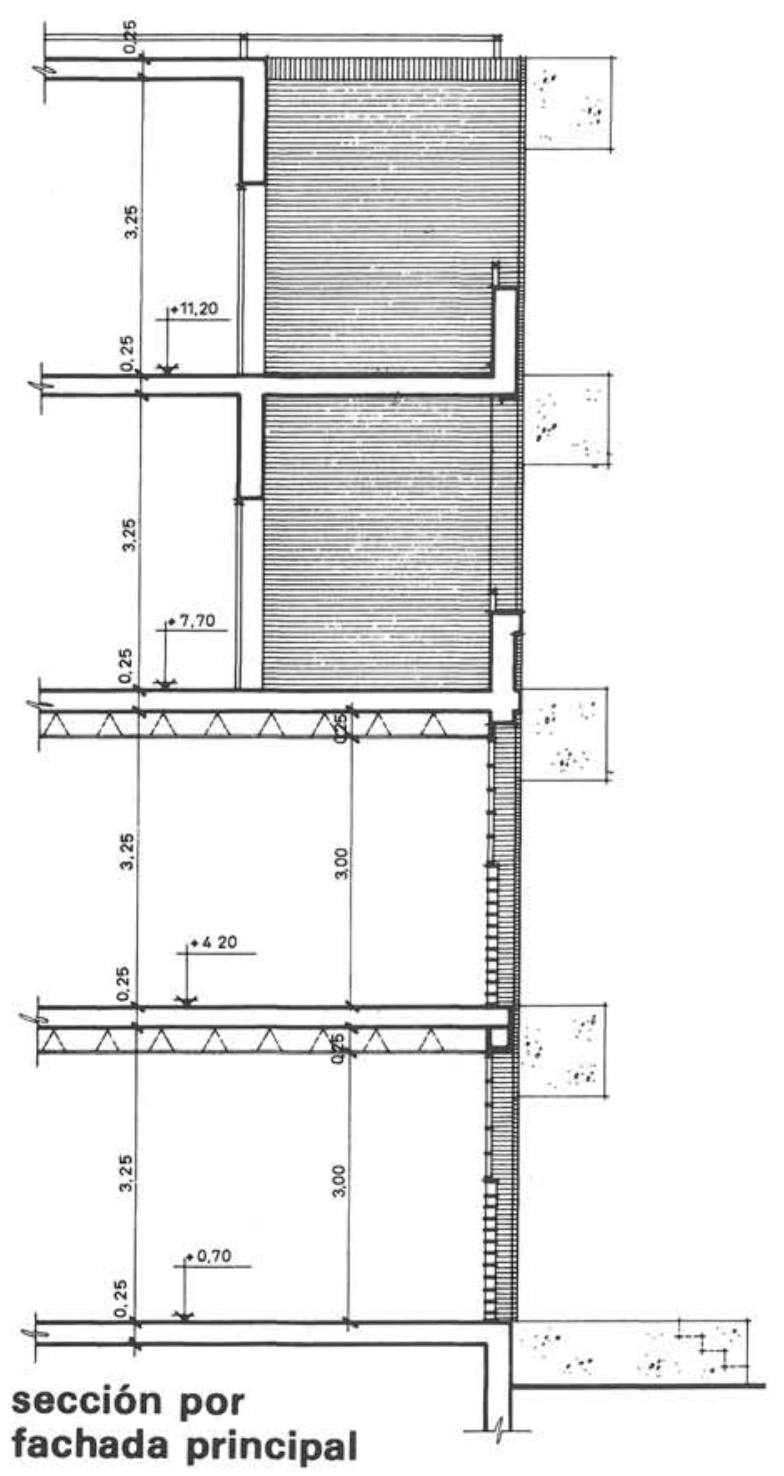

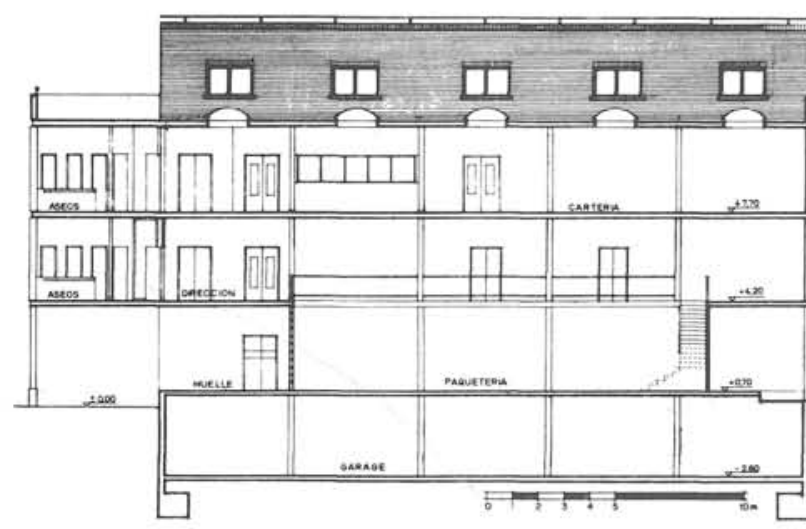

sección A-A

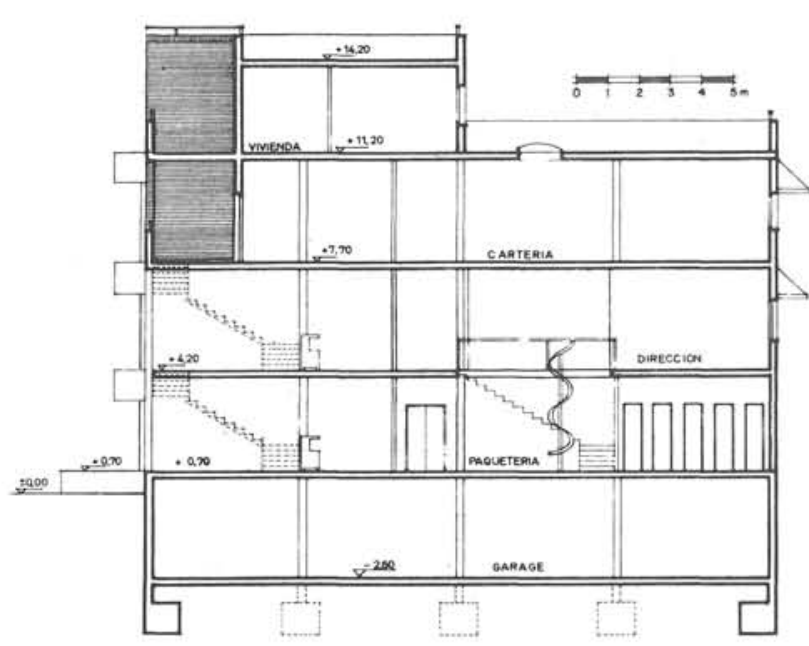

sección B-B

esta planta se llevan a cabo por la rampa de vehículos al fondo y la escalera y el ascensor de funcionarios.

\section{Planta baja}

La planta baja destinada principalmente a la paqueteria, se relaciona con los dos muelles, uno al lado de las vías y el otro por la zona de entrada de camiones a través de una sala de trabajo la cual, a su vez, está enlazada con la Sala de Dirección situada en el nivel superior mediante escalera, tolva y el montacargas que recorre todo el edificio. En esta planta se encuentran los accesos desde la caIle. Por el portal destinado al público se accede a un ascensor que permite llegar cómodamente a los vestibulos superiores.

\section{Planta primera}

Esta planta consta de vestíbulos para la estafeta, zona de administración y sala de dirección, así como aseos y vestuarios. 


\section{Planta segunda}

Es la destinada a cartería, con los servicios al público de apartados, lista y reembolsos. Consta además de aseos, vestuarios y un archivo.

\section{Planta tercera}

En esta planta están alojados los cuartos de maquinaria de los ascensores, asi como una vivienda de $110 \mathrm{~m}^{2}$.

La superficie total construida fue de $2.290 \mathrm{~m}^{2}$; 1.793 sobre rasante y 497 en planta sótano.

Los sistemas, materiales y elementos constructivos utilizados en este edificio fueron los siguientes: cimentación y muros de contención en sótano de hormigón armado, soportes de acero laminado, forjados reticulares bidireccionales, fachadas de ladrillo prensado, cubiertas con acabado de grava y pavimentos de gres y polibetón.

La carpintería exterior es de aluminio sobre marcos de acero, y las divisiones interiores se realizaron a base de mamparas hechas con tabicón y tubo de hierro pintado al esmalte.

Respecto a instalaciones podemos decir que para la del acondicionamiento de aire se hicieron dos chimeneas para la distribución vertical en los núcleos de circulaciones verticales, mientras que para la distribución horizontal se utilizó el hueco existente entre el cielorraso de escayola y el forjado.

Tanto en este edificio, como en los otros dos que se describen en este artículo, se ha tratado de armonizar su arquitectura con el entorno circundante dándoles el mayor realce -dentro de las posibilidades de cada emplazamiento- a cada uno de los edificios.

\section{Edificio de comunicaciones en Santa Cruz de Tenerife}

En el Puerto de la Cruz se ha realizado este nuevo edificio de la Dirección General de Correos y Telecomunicación, constituido por un edificio de comunicaciones y un cuerpo adosado que alberga 2 viviendas para los Jefes Provinciales.

La parcela, situada en la confluencia de dos calles, tiene la forma de un trapecio muy alargado y una superficie próxima a los $1.400 \mathrm{~m}^{2}$.

La forma de la parcela y sus restrictivas condiciones urbanisticas motivaron la configuración longitudinal del edificio, desarrollado a lo largo de la calle principal y con retranqueos en la zona trasera para adaptarse al perfil quebrado del lindero posterior.

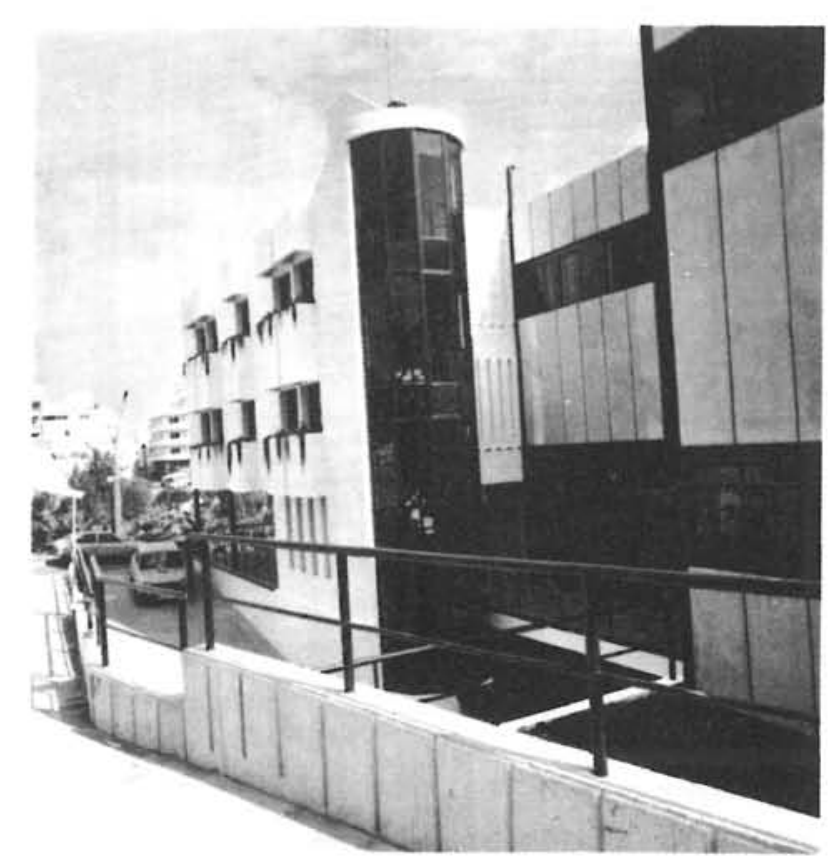

http://informesdelaconstruccion.revistas.csic.es 


\section{plantas}

planta baja

sótano

$\operatorname{cota}-2,80 \mathrm{~m}$
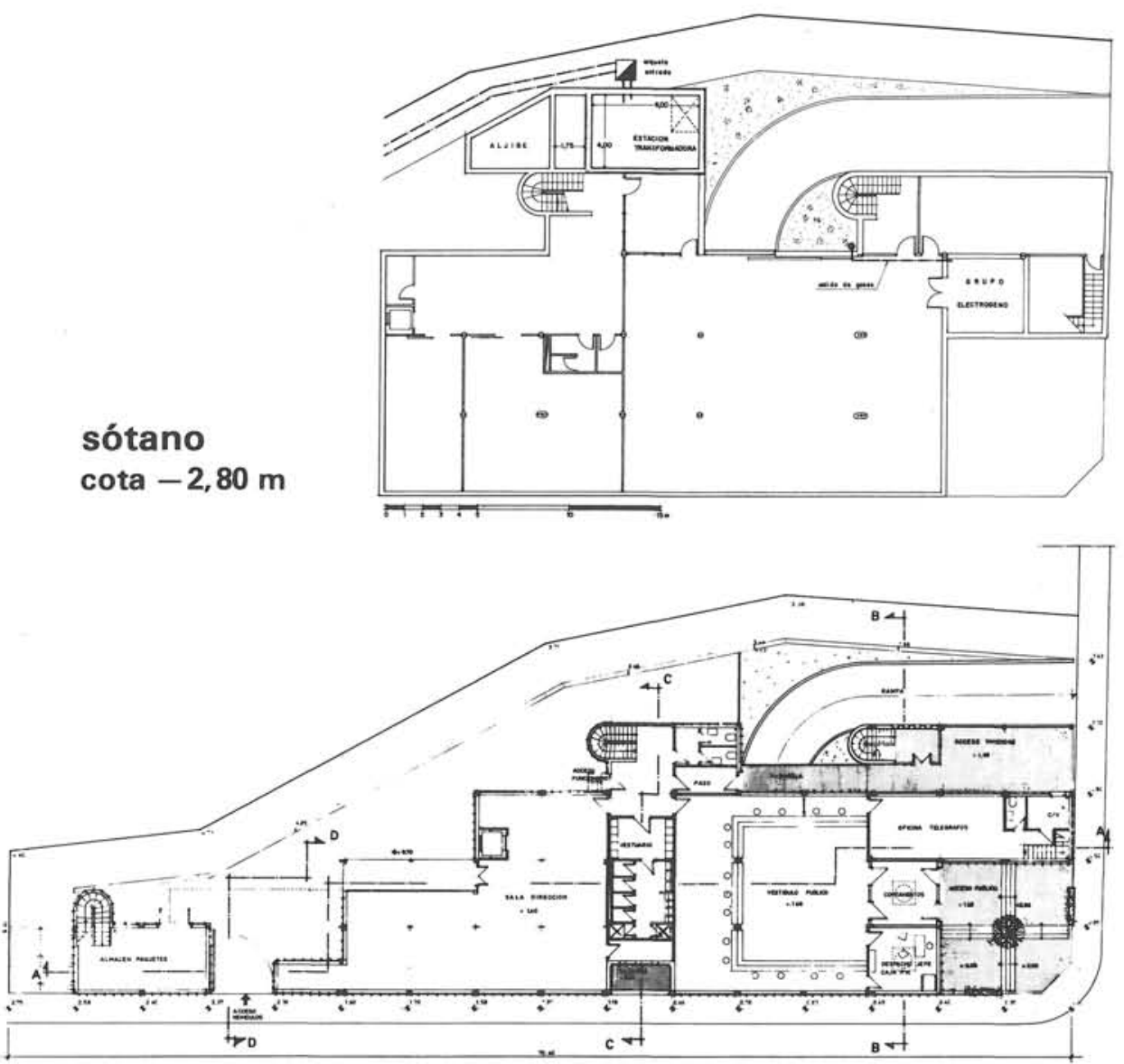

planta primera cota oficina $+5,80 \mathrm{~m}$ cota viviendas $+4,50$ y $+7,25 \mathrm{~m}$

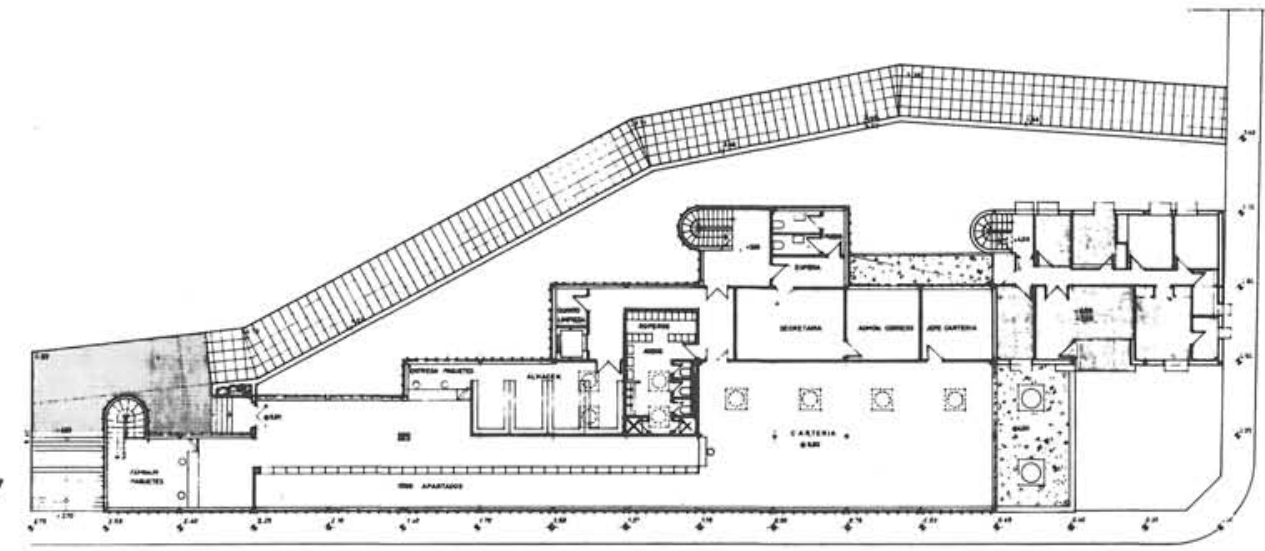

\section{planta de viviendas cota $+4,50 y+7,25 m$}

Superficie construida Superficie útil

1.-Despacho $\left(6,20 \mathrm{~m}^{2}\right)$. 2. - Dormitorio $\left(8,70 \mathrm{~m}^{2}\right)$. 3. - Dormitorio $\left(8,70 \mathrm{~m}^{2}\right)$. 4.-Dormitorio $\left(8,19 \mathrm{~m}^{2}\right)$. 5.-Tendedero $\left(2,60 \mathrm{~m}^{2}\right)$. 6. - Cocina $\left(9,46 \mathrm{~m}^{2}\right)$. 7. - Salón-estar $\left(21,56 \mathrm{~m}^{2}\right)$. 8.-Dormitorio principal $\left(13,35 \mathrm{~m}^{2}\right)$. $126,80 \mathrm{~m}^{2}$

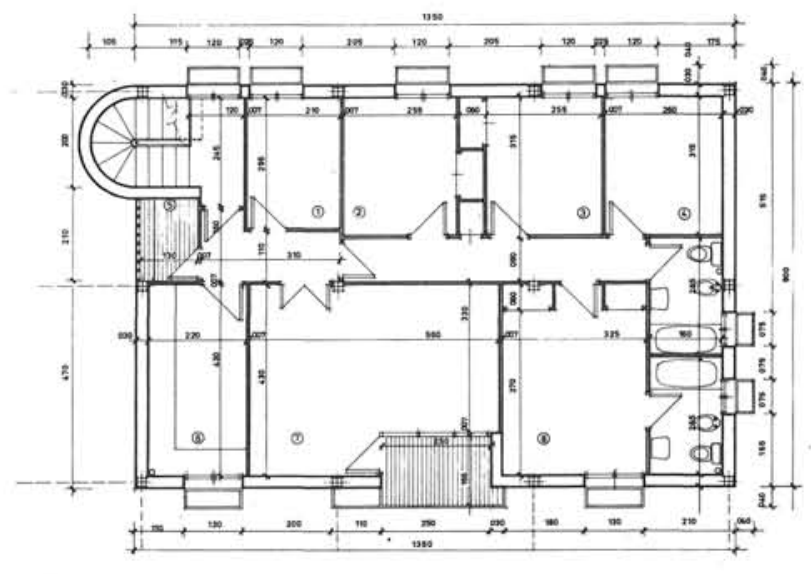




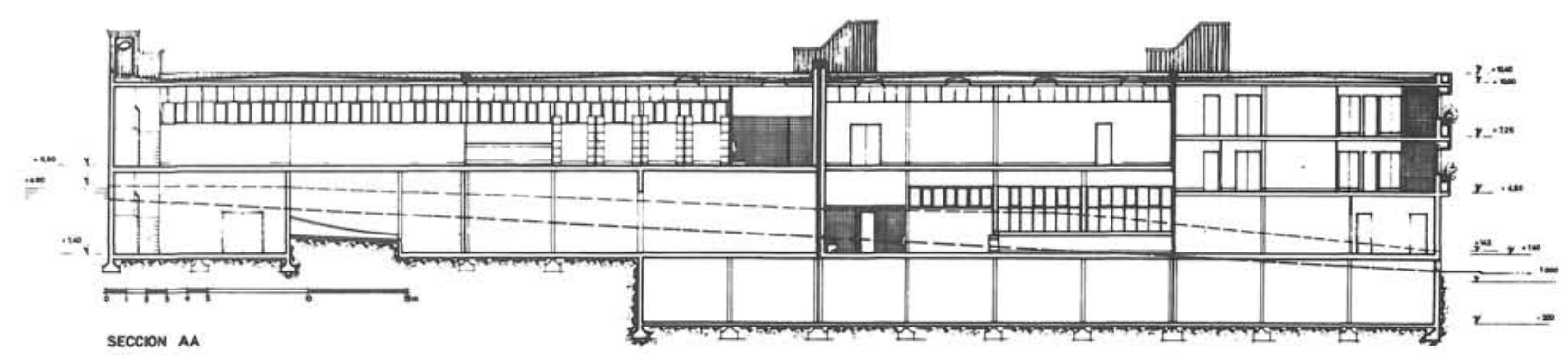

sección longitudinal A-A

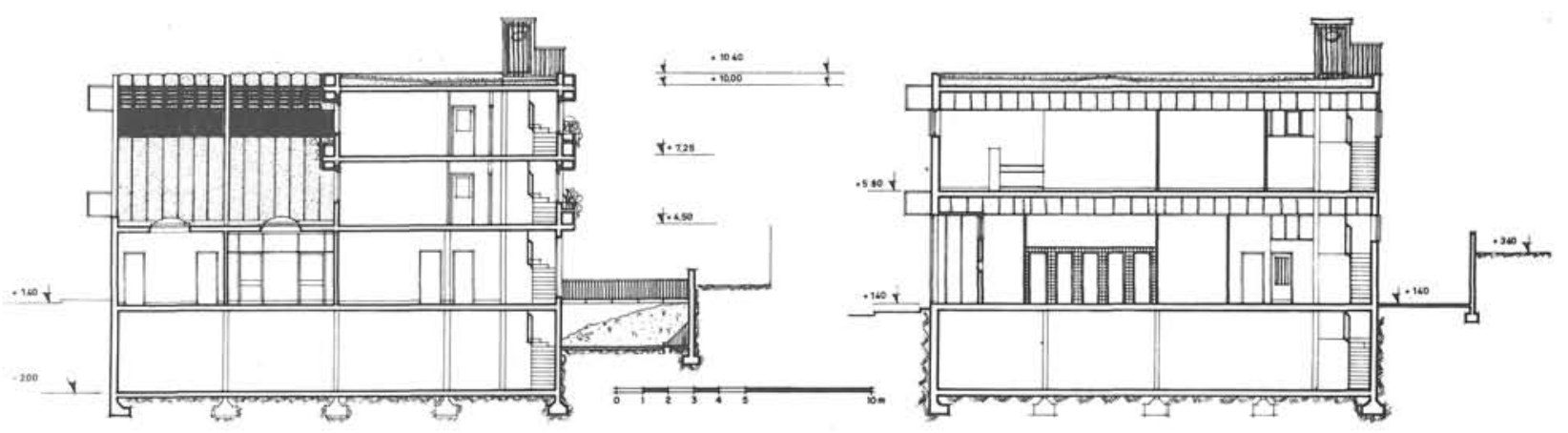

secciones transversales B-B y C-C

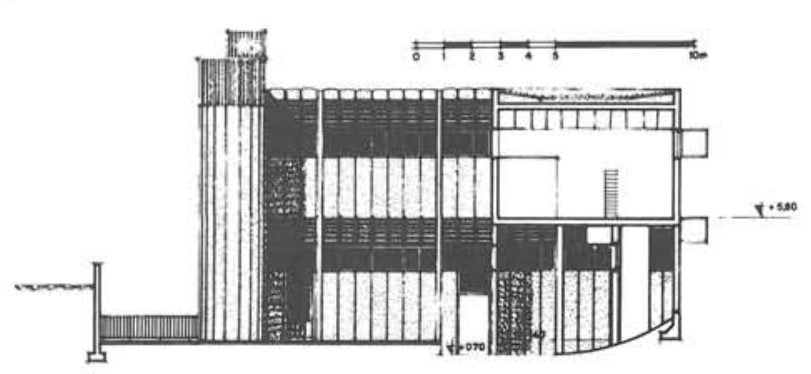

sección transversal D-D
La construcción consta de dos plantas sobre rasante y un sótano que proporcionan superficie suficiente para satisfacer el programa de necesidades establecido por la Jefatura Provincial. Cada una de las plantas superiores tiene una altura libre de $4,20 \mathrm{~m}$, previendo una mecanización suspendida de los techos para el transporte de las sacas.

La entrada principal, en planta baja, se sitúa en la confluencia de las dos calles, como lugar más noble y de más clara relación para el público. Está tratada como un amplio atrio descubierto que se prolonga por unos soportales bajo el bloque de viviendas.

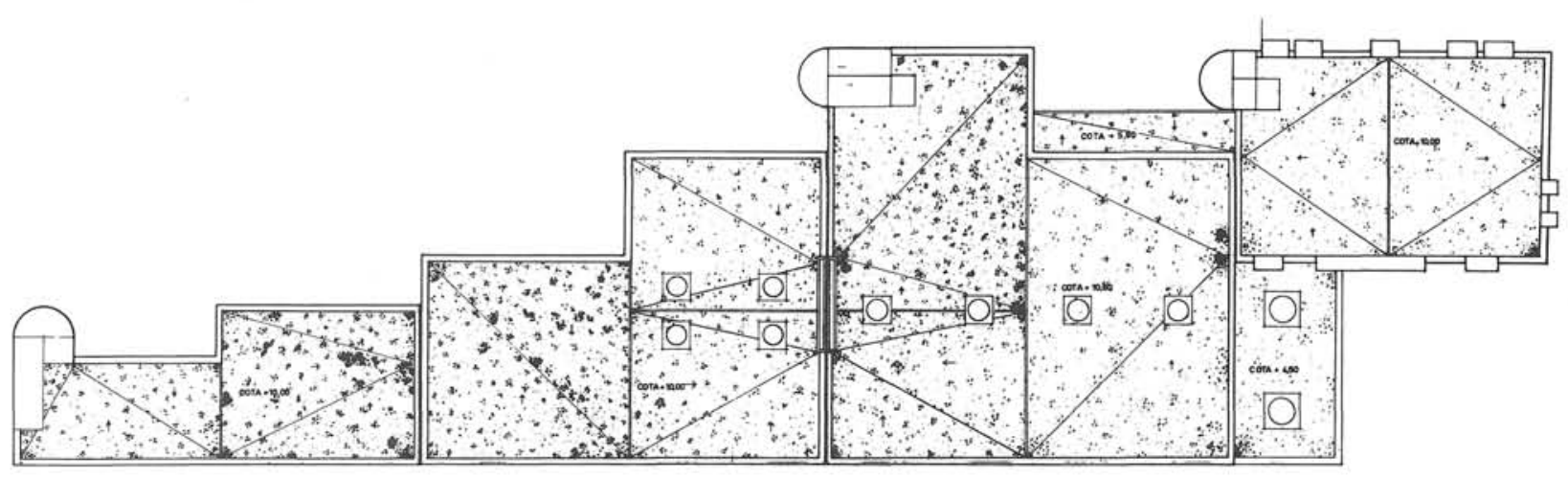

planta de cubierta cota $+4,50 y+10,00 m$ 


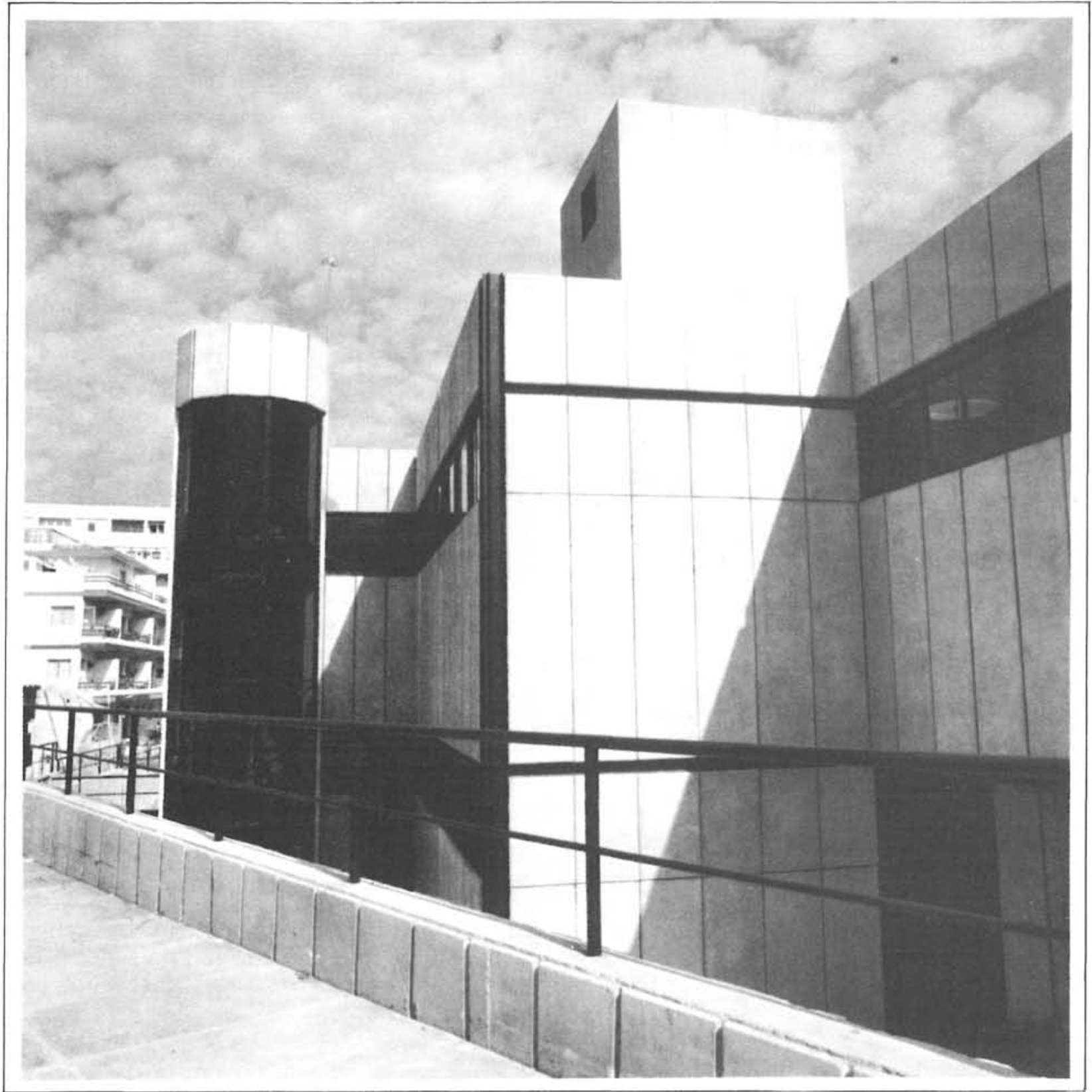

La planta superior tiene su acceso por la esquina opuesta, aprovechando el desnivel del terreno.

El bloque de viviendas, aunque adosado al edificio principal por el testero, se ha concebido como un cuerpo independiente, para evitar interferencias en las circulaciones.

Rodeando al edificio por la zona interior, una vía privada enlaza las dos calles y proporciona acceso a los muelles de carga y descarga.

En planta baja se sitúa el vestíbulo principal de atención al público, dotado de cortavientos y con acceso directo desde el atrio de la es-

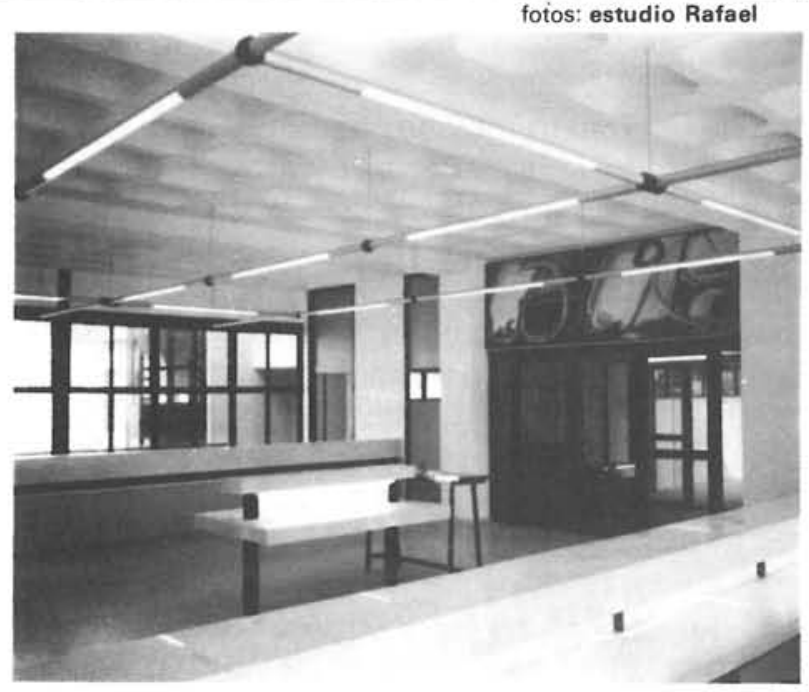




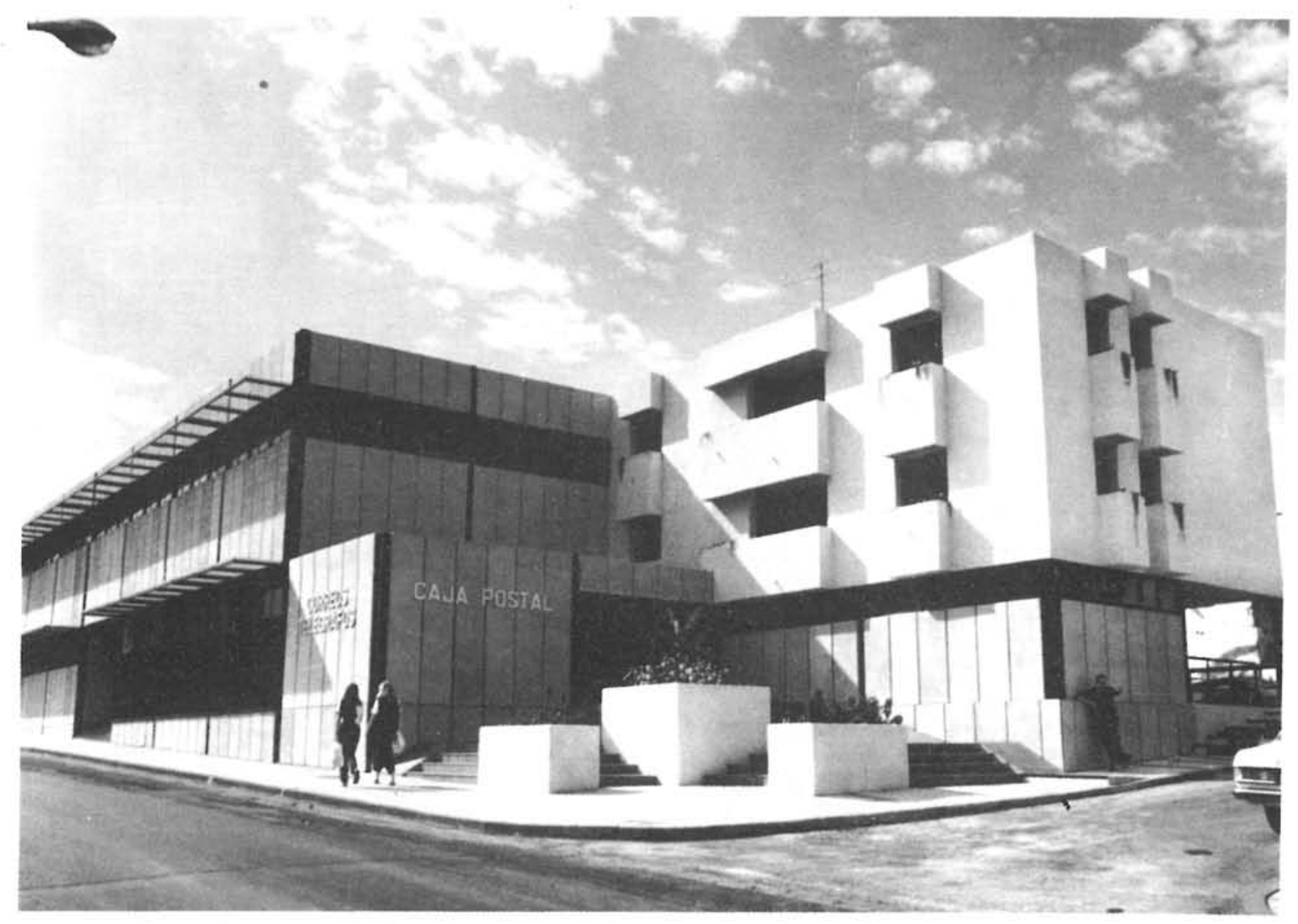

quina. Su perímetro lo delimitan una estafeta de Telégrafos, el despacho de la Caja Postal de Ahorros y un mostrador con los distintos servicios postales. Esta zona de servicios comunica con la sala de dirección y apertura, enlazada a su vez con el muelle y la boca de buzones. En una esquina de esta sala, al lado del muelle, se sitúa el núcleo de circulaciones verticales de objetos postales, con montacargas y tolva helicoidal.

En el otro extremo de la calle, una ancha escalinata conduce a una plataforma de entrada a un segundo vestíbulo público, en el que se encuentra el negociado de paquetes postales. Este segundo vestíbulo le limitan los mostradores de admisión y entrega de paquetes -equipado este último con almacén-, un frente de casilleros de apartados y el mostrador de cartería. La planta se completa con la zona administrativa y un núcleo de servicios.

Bajo la rasante se han situado el garaje, almacenes y las instalaciones del edificio.
Las dos viviendas de los jefes ocupan un bloque rectangular con acceso desde el soportal que comunica con el atrio. Sus cuatro fachadas son exteriores y su programa lo componen tres dormitorios dobles, comedor-estar, cocina, dos cuartos de baño, despacho, tendedero y vestíbulo.

En la construcción se ha empleado una estructura compuesta por soportes de acero laminado y forjados reticulares bidimensionales.

Para los cerramientos del edificio principal se utilizó un chapado de piedra artificial sobre doble fábrica de bloque hueco de hormigón. En las viviendas el revestimiento exterior se hizo con un revoco de tono parecido al de la piedra artificial. Asi, aunque cada uno de los dos cuerpos manifiesta su función a través de su distinto tratamiento, ambos entonan adecuadamente dentro de la unidad que constituyen. 